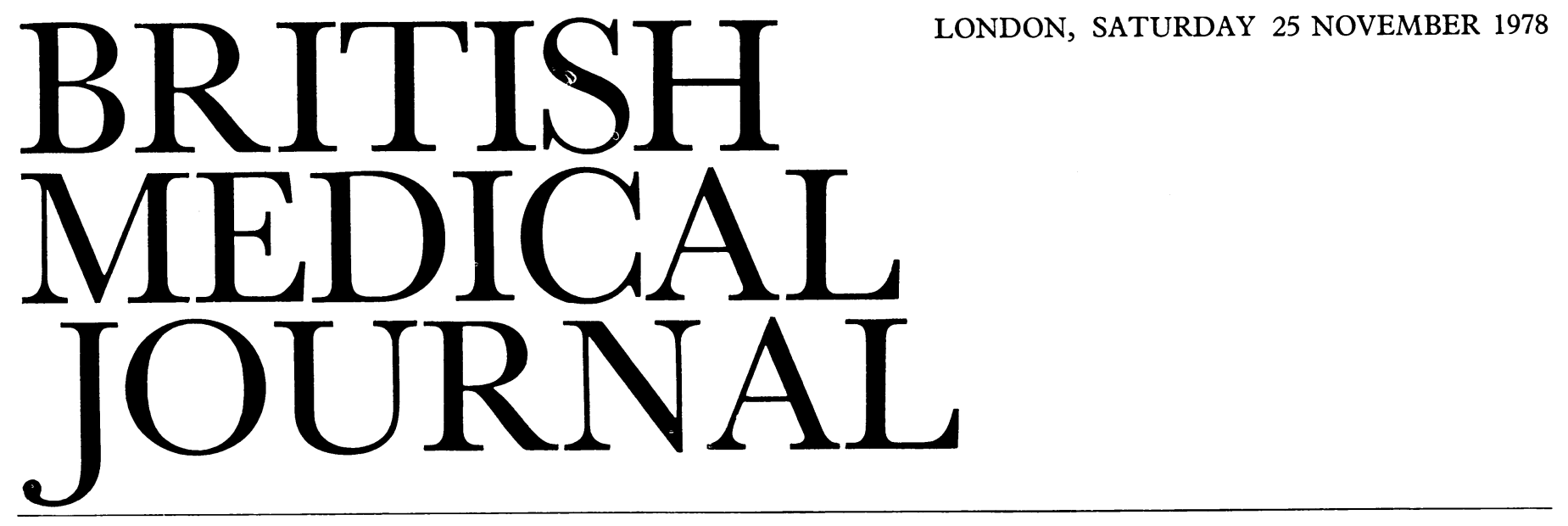

\title{
Selection of patients for dialysis and transplantation
}

Fifteen years ago treatment by intermittent haemodialysis in Scribner's pioneer outpatient centre was reserved for patients selected because of their youth and lack of disease in organs other than the kidney. ${ }^{1}$ Since those early days the criteria for selection have been progressively relaxed.

Changing clinical practice is reflected in the mean age of new patients accepted for dialysis and transplantation and in the proportion of diabetics accepted. The mean age of patients accepted in Europe rose year by year from 37 years in 1970 to 45 in 1977..$^{2}$ Diabetics were mostly excluded from treatment in 1970, accounting for only two out of every thousand new patients. ${ }^{3}$ In 1977 , however, there were 40 diabetics in every thousand new patients. ${ }^{2}$ In the United States of America the criteria have become even less stringent than in Europe. The mean age of patients being treated with dialysis was five years more than that of European patients in 1975 and climbing at the same rate. ${ }^{4}$ Now American patients well past retiring age may be put on dialysis. In Britain, by contrast, the mean age of new patients rose from 34 in 1970 to 38 in 1977, seven years less than for Europe as a whole. ${ }^{2}$

A questionnaire circulated among European centres asked about selection policies in 1977. In Europe as a whole $70^{\circ}$ of centres imposed no age limit, 22 " , had a general rule to exclude patients aged more than 65 , and $8^{\circ}$ " had a general rule to exclude patients aged more than 55 . In the United Kingdom only $18^{\circ}$ " of centres did not have an age limit; $45^{\circ}$ "generally excluded patients aged over 65 and $37^{\circ}{ }^{\circ}$, those aged more than $55 .^{2}$

Thus differences in selection policy undoubtedly exist between centres in Britain and other European countries. In 1977 the number of new patients accepted for dialysis and transplantation exceeded 50 per million of population in the United States and Japan; in the larger European countries it was 33 in France, 30 in the Federal Republic of Germany, 26 in Italy, and 22 in Spain. In Britain only 16 patients per million of population were treated. ${ }^{2}$ If children alone are considered, 11 European countries, including East and West Germany, France, and Spain, accepted relatively more new patients than did Britain. ${ }^{5}$ There is no evidence that the need is different. All epidemiological studies in Britain indicate that about 40 patients per million population who are suitable for dialysis or transplantation reach terminal renal failure each year. ${ }^{6}$

This difference in numbers of patients has been related to the smaller number of centres ${ }^{7}$ and of consultants in nephrology ${ }^{8}$ in Britain. Pressure on limited facilities for new patients must result in more stringent selection. The types of treatment that are available also influence selection. Haemodialysis in hospital can seldom be offered as definitive long-term treatment in Britain, and less than $20 \%$ of British patients were having this treatment in hospital in 1977 compared with over $60^{\circ}$ of European patients. ${ }^{2}$ British patients are therefore accepted with a view to home dialysis and transplantation and in 1977 these two modes of treatment each supported about $40 \%$ of our 4441 patients. Selecting patients according to their suitability for home dialysis and transplantation must clearly be more restrictive than selecting them for long-term hospital treatment.

Earlier this year the Budget acknowledged the shortcomings of the NHS in treating patients with kidney disease, and a real political intention to relax constraints on resources is now evident. If more patients are accepted next year for dialysis and transplant programmes in Britain more older patients and more patients with multisystem diseases, such as diabetes, are likely to be treated. An expansion of hospital dialysis-in, for example, so-called satellite or self-care units-will enable patients who are not suitable for home dialysis or transplantation to be accepted. Relaxing resource constraints means relaxing selection criteria. Patients accepted for treatment will make more demands. We welcome the political decision to free more NHS resources for dialysis, but any offer of kidney machines alone is not enough: an increase in treatment centres and in nursing and medical staff will also be necessary. Recruitment and training of nurses for this work must be encouraged as a matter of urgency. Long-term planning for extending the service requires a clear lead from the Department of Health in setting regional targets for numbers of dialysis and transplantation centres and for the appointment of new consultants. We should also have a yearly co-ordinated review of progress.

Not all selection, however, is the result of scarce resources. Some centres report that they can cope with the patients referred to them, and selection may therefore be occurring earlier, either because the diagnosis is not made in time or because the doctor decides not to refer the patient for specialised care. Selection policies also apparently vary among centres in Britain. Traditionally doctors have accepted that the decision not to offer inappropriate treatment is a proper medical responsibility. In the absence of personal financial incentive to treat more patients with dialysis the NHS doctor 
is more free to decide that these extraordinary procedures for prolonging life do not confer a good enough quality of life to make them suitable for all patients dying of renal failure. Not to treat may be kinder and wiser. Nevertheless, much of the present disquiet over selection of patients for dialysis and transplantation under the NHS is being voiced by organisations representing patients. Their views and the whole policy need a full and frank debate in the open.

\footnotetext{
1 Lindholm, D D, Burnell, J M, and Murray, J S, Transactions of the American Society for Artificial Internal Organs, 1963, 9, 3.

2 Wing, A J, et al, Proceedings of the European Dialysis and Transplant Association, 1978, 15, 3.

3 Drukker, W, et al, Proceedings of the European Dialysis and Transplant Association, 1970, 7, 3.

4 Gurland, H J, et al, Proceedings of the European Dialysis and Transplant Association, 1975, 13, 3.

${ }^{5}$ Donckerwolcke, R A, et al, Proceedings of the European Dialysis and Transplant Association, 1978, 15, 77.

6 Office of Health Economics, Renal Failure-a Priority in Health? London, Office of Health Economics, 1978.

7 Wing, A J, et al, in Dialysis Review, ed A M Davison, p 40. Tunbridge Wells, Pitman Medical, 1978.

${ }^{8}$ Executive Committee of the Renal Association, British Medical fournal, 1976, 2, 903.
}

\section{Young people who sleep badly}

\author{
Where unbruised youth with unstuff'd brain \\ Doth couch his limbs, there golden sleep doth reign
}

Friar Laurence in Romeo and fuliet wistfully expressed a feeling common among the middle-aged-that the young are endowed with easier sleep. Surveys of 2500 people in Scotland ${ }^{1}$ and 1600 in Florida ${ }^{2}$ have confirmed that the older people become the more they are dissatisfied with their sleep, and the more often they take pills for it, especially women. Nevertheless, among the 400 15-24-year-olds in the Scottish study there were $5 \%$ who regarded their sleep as disturbed and often took pills, whether prescribed drugs or remedies bought from pharmacists; while $6 \%$ of the 18-19-year-olds in Florida said that they found it difficult to sleep.

Poor sleepers of all ages think they are troubled by their nerves, and the young are no exception. Monroe ${ }^{3}$ selected from among 200 a group of 16 (median age 23) who considered themselves particularly poor sleepers and a similar group of 16 particularly good sleepers. The groups differed in their responses to the Cornell Medical Index and to a personality inventory, the poor sleepers appearing to have a depressed outlook. Johns, ${ }^{4}$ with 104 medical students of mean age 21, also found that complaints of poor sleep and nightmares were associated with psychological problems, and especially with low self-esteem. Over half of another group of 48 patients, aged 18-29, who had come with a primary complaint of insomnia, ${ }^{5}$ were depressed; while in an American national survey of adolescents who were receiving psychotherapy poor sleepers consistently presented more neurotic features and the good sleepers more psychopathic characteristics. ${ }^{6}$ Monroe also compared his good and poor sleepers in a sleep laboratory, and found differences such as higher heart rates and body temperatures through the night in the poor sleepers. Johns ${ }^{7}$ found higher corticosteroid concentrations throughout the 24 hours, which suggests that in those who think they are poor sleepers conditions may indeed be less favourable for the tissue restoration that is associated with sleep. ${ }^{8}$
In a sample of 639 American highschool pupils $12 \%$ thought they had persistent sleep problems, including taking 45 minutes or more to fall asleep at least three times a week and wakening in the night for 30 minutes or more at least three times a week. ${ }^{9}$ There were more girls than boys, and they were distinguished from the other adolescents by worry and tension; personal and family problems; low self-esteem; and feeling moody and "down in the dumps" most of the time.

The results of this survey suggest that, as with adults, the psychological problems are primary and lead to the complaints of poor sleep. Among the 23 pupils who said that they usually had only three to five hours' sleep were 12 who were chronically poor sleepers, but the other 11 had no complaints and were categorised as good sleepers.

The authors of this Californian study urge that these young people should be recognised more often both by teachers and by doctors and other health workers. They might be helped through "self-management" and education in such techniques as progressive muscle relaxation and meditation. But, most important, they recommend that the doctor should avoid prescribing hypnotics for these poor sleepers.

${ }^{1}$ McGhie, A, and Russell, S M, Fournal of Mental Science, 1962, 108, 642.

2 Karacan, I, et al, Social Science and Medicine, 1976, 10, 239.

${ }^{3}$ Monroe, L J, Fournal of Abnormal Psychology, 1967, 72, 255.

${ }^{4}$ Johns, M W, Bruce, D W, and Masterton, J P, British fournal of Medical Psychology, 1974, 47, 181.

${ }^{5}$ Kales, A, et al, Archives of General Psychiatry, 1976, 33, 1128.

6 Monroe, L J, and Marks, P A, Fournal of Clinical Psychology, 1977, 33, 263.

7 Johns, M W, et al, Psychosomatic Medicine, 1971, 33, 499.

8 Adam, K, and Oswald, I, Fournal of the Royal College of Physicians, 1977, 11, 376.

${ }^{9}$ Price, V A, et al, American fournal of Diseases of Children, 1978, 132, 583.

\section{Freeze-dried factor VIII concentrates and the NHS}

Bleeding in classical haemophilia (haemophilia A) is due to a deficiency of factor VIII coagulant activity, and its treatment consists in giving intravenous injections of material rich in this factor. Human factor VIII is best, but in patients who have antibodies to factor VIII animal factor VIII may also be of value.

At present human factor VIII is available in Britain in the form of cryoprecipitate prepared by the National Blood Transfusion Service or as a freeze-dried protein concentrate prepared by the NHS fractionation laboratories in London, Edinburgh, and Oxford. The introduction ${ }^{1}$ of cryoprecipitate as a source of factor VIII in 1964 was an important step forward in the management of haemophilia and did much to improve the lot of haemophiliacs, but it is difficult material to handle, is variable in potency from bag to bag, and needs to be stored at temperatures below $-20^{\circ} \mathrm{C}$. In contrast, the freeze-dried factor VIII concentrates have the advantages of known potency, stability at $+4^{\circ} \mathrm{C}$, ease of reconstitution before transfusion, and a low risk of allergic reactions. These advantages are of particular importance now that home treatment is being used increasingly in the management of haemophilia, ${ }^{2}$ and haemophilia centre directors generally agree that most if not all of the material used to treat haemophilia in Britain should be freeze-dried concentrate, preferably made within the NHS. ${ }^{3}$

Unfortunately, the amount of factor VIII concentrates made by the NHS fractionation laboratories still falls far short 